\title{
Obestatin: A New Element for Mineral Metabolism and Inflammation in Patients on Hemodialysis
}

\author{
Antonio Lacquaniti $^{a}$ Davide Bolignano $^{a}$ Valentina Donato $^{a}$ Valeria Chirico $^{b}$ \\ Adolfo Romeo $^{a}$ Saverio Loddo ${ }^{c}$ Michele Buemi ${ }^{a}$ \\ Departments of anternal Medicine, ${ }^{b}$ Pediatric Sciences, and ${ }^{c}$ Pathology, University of Messina, Messina, Italy
}

\section{Key Words}

Hemodialysis · Inflammation · Malnutrition · Mineral

metabolism · Obestatin

\begin{abstract}
Background: Obestatin plays a key role in the process of energy balance maintenance with an anorectic effect. The main aim of the study was to evaluate obestatin in uremic patients to determine whether it is correlated with nutritional and inflammatory status. Methods: We studied plasma obestatin in uremic patients $(n=50)$ undergoing hemodialysis therapy and in healthy subjects. Plasma obestatin was measured using an ELISA kit. Results: Obestatin levels in uremic patients were lower than in healthy subjects $(p<$ $0.0001)$. Patients with a body mass index (BMI) $>23$ had lower obestatin levels than those with a BMI $<23(p=0.001)$. After multivariate analysis, direct correlations were maintained between obestatin and high-sensitivity $\mathrm{C}$-reactive protein $(\beta=0.68, p<0.0001)$ and total alkaline phosphatases $(\beta=$ $0.30, p=0.03)$, while inverse correlations were found with iron $(\beta=-0.32, p=0.002$ ) and calcium-phosphorous product $(\beta=-0.40, p=0.001)$. Conclusions: Based on the present observational data, obestatin might be implicated in the inflammatory state and the disturbances of calcium/phos-
\end{abstract}

phate metabolism of hemodialysis patients. However, further studies are warranted to determine whether this hormone plays a key role in contributing to malnutrition and to the chronic inflammatory process.

Copyright $\odot 2011$ S. Karger AG, Basel

\section{Introduction}

The hormone obestatin, made up of 23 amino acids with a molecular weight in the region of 2,500 daltons and synthesized in the stomach, is produced through a post-translational cleavage process undertaken by a precursor, preproghrelin, from which ghrelin, its antagonist, also originates [1].

Obestatin is not only found in the gastrointestinal tract, but also in the spleen and maternal milk, and it is present in the mammary gland tissue, the kidney, the thyroid gland, and circulating plasma [2].

From a functional viewpoint, obestatin has been cited in the complex hormonal network that regulates the energy balance in humans, with an anorectic effect. This hormone, in fact, causes a reduction in food intake through a peripheral action, slowing down gastric emptying and jejunal motility, also at central level, acting on 
the hunger center via the hypothalamus [3]. These effects are counterbalanced by those of the counterregulating hormone, ghrelin, which has an orexigen effect [4].

Malnutrition is a typical element in patients with terminal renal failure and an important predictive factor for mortality exerting a negative action on the evolution of the disease [5]. Among the various causes of protein-energy metabolism, alterations are hormonal imbalance and gastrointestinal disturbances attributable to uremic toxins, and concomitant diseases, such as diabetes mellitus or systemic vascular disease [6].

Furthermore, several important epidemiological data also show a strong correlation between malnutrition and the chronic inflammatory status characterizing uremic patients $[7,8]$, so much so that the term 'malnutritioninflammation complex syndrome' has been proposed to indicate the co-causality of the two conditions [9]. A useful system for identifying this condition is the so-called malnutrition-inflammation score (MIS), an inexpensive, easily administered questionnaire designed to analyze clinical and laboratory anthropometric parameters appropriate for identifying inflammatory status and nutritional condition [10].

The aim of the present study was to analyze obestatin levels in uremic patients given three weekly sessions of hemodialysis (HD) in order to evaluate the potential relationship of the hormone with different biohumoral, nutritional, inflammatory, anthropometric and hematochemical parameters.

\section{Patients and Methods}

\section{Patients and Controls}

The study series consisted of 50 patients with end-stage renal disease on intermittent HD treatment ( 25 women $(50 \%)$ and 25 men (50\%), mean age $63.9 \pm 16$ years, mean body mass index (BMI) $21.5 \pm 4.6$ ). The criteria for inclusion in the study were: age $>18$ years and dialytic age of at least 6 months. Patients with inflammatory disease or a diagnosis of cancer were excluded from the study. The HD sessions, of 3-4 h duration, took place 3 times a week; blood flow was $>250 \mathrm{ml} / \mathrm{min}$, bicarbonate infusion 2,000 $\mathrm{ml} / \mathrm{h}$, the acetate-free biofiltration technique being employed, with the Integra monitor (Hospal, Bologna, Italy). The causes of renal failure were diabetes $(n=25)$, nephroangiosclerosis $(n=10)$, chronic glomerulonephritis $(n=6)$, polycystic kidney $(n=2)$ and other causes $(n=7)$. An evaluation was also made of 20 healthy volunteers (10 women and 10 men, mean age $52.8 \pm 4.7$ years, mean BMI $23.2 \pm 2$ ) with a clinical history negative for arterial hypertension, diabetes mellitus, cancer, cardiovascular, pulmonary, inflammatory, renal and endocrinal disease. The study was approved by the local ethics committee, and fully informed consent was obtained in writing from all participants.
Management of Blood Samples

In patients receiving $\mathrm{HD}$, blood samples were collected in the morning at 08:00 h immediately before and just after hemodialysis from the arterial line of the HD, while in a healthy control group, blood samples were collected at 08:00 h following an overnight fast. Blood samples were collected into chilled vacutainer tubes containing potassium ethylenediamine tetracetate. Tubes were instantly cooled on ice and centrifuged at 3,000 rpm for 10 min at $4^{\circ} \mathrm{C}$ within $30 \mathrm{~min}$. Plasma was stored at $-80^{\circ} \mathrm{C}$ until analyzed.

\section{Laboratory Methods}

Plasma obestatin was measured using a commercial available ELISA kit (Bachem Distribution Services GmbH, Weil am Rhein, Germany), according to the manufacturer's instructions. All specimens were diluted often to obtain concentration for the optima density according to the ELISA kit instruction. The enzymatic reactions were quantified in an automatic microplate photometer. All measurements were made in a triplicate and blinded manner. Obestatin levels were expressed as nanograms per milliliter (ng/ml).

Common biochemical parameters, including urea, creatinine, uric acid, serum lipids, total serum calcium, phosphorus, calcium-phosphate product, serum iron, electrolytes, albumin, hemoglobin, total alkaline phosphatases, proteinuria, fibrinogen, homocysteine, $\beta_{2}$-microglobulin and high-sensitivity C-reactive protein (hsCRP) were measured at baseline in all patients and controls, according to standard methods in the routine clinical laboratory. Intact parathyroid hormone (PTH) was also measured by immunoradiometric assay using Elecsys 2010 autoanalyzer system (Roche Diagnostics, Basel, Switzerland). The normal range was 7-20 mg/dl for urea, $0.5-1.2 \mathrm{mg} / \mathrm{dl}$ for creatinine, $2.5-$ $7.0 \mathrm{mg} / \mathrm{dl}$ for uric acid, $3.5-5 \mathrm{~g} / \mathrm{dl}$ for albumin, $8.5-10.2 \mathrm{mg} / \mathrm{dl}$ for calcium, 2.5-5 mg/dl for phosphorus, 40-120 IU/l for alkaline phosphatase (ALP), $0.3-8.0 \mathrm{mg} / \mathrm{l}$ for hsCRP, 10-70 $\mathrm{pg} / \mathrm{ml}$ for PTH, 0.8-2.5 mg/dl for $\beta_{2}$-microglobulin, 4.5-10 mg/dl for homocysteine, $130-200 \mathrm{mg} / \mathrm{dl}$ for total cholesterol, $45-155 \mathrm{mg} / \mathrm{dl}$ for triglycerides, $60-160 \mu \mathrm{g} / \mathrm{dl}$ for serum iron, $200-360 \mathrm{mg} / \mathrm{dl}$ for transferrin, $20-45 \%$ for TSAT, 18-250 $\mathrm{ng} / \mathrm{ml}$ for ferritin, and 13$16 \mathrm{~g} / \mathrm{dl}$ for hemoglobin.

\section{Malnutrition Inflammation Score}

The MIS is a comprehensive scoring system with significant strong correlations with prospective hospitalization indices, mortality, and surrogates for nutrition and inflammation of uremic patients.

It consists of four sections (nutritional history, physical examination, BMI, and laboratory values). The history section includes five components adopted from the original Subjective Global Assessment, a semiquantitative scoring system, commonly used in nephrology, based on history and physical examination. The history consists of five components: weight loss during the preceding 6 months, gastrointestinal symptoms, food intake, functional capacity, and co-morbidities. Each of these features is scored separately as A, B, or C, reflecting well-nourished to severely malnourished categories. The physical examination includes two components: loss of subcutaneous fat and muscle wasting. The third marker is represented by BMI, a ratio of enddialysis weight $(\mathrm{kg})$ to height squared $\left(\mathrm{m}^{2}\right)$, to represent heightstandardized weight. The fourth MIS section includes two labora- 
Table 1. Baseline demographic, clinical and laboratory data of the study population

\begin{tabular}{lccc}
\hline Parameter & HD patients $(\mathrm{n}=50)$ & Healthy subjects $(\mathrm{n}=20)$ & p value \\
\hline Male/female & $25 / 25$ & $10 / 10$ & - \\
Age, years & $63.9 \pm 16$ & $52.8 \pm 4.7$ & 0.003 \\
BMI & $21.5 \pm 4.6$ & $23.2 \pm 2$ & 0.13 \\
Albumin, g/dl & $3.8 \pm 6$ & $4.09 \pm 0.40$ & 0.02 \\
Calcium, mg/dl & $8.6 \pm 0.9$ & $9.14 \pm 0.4$ & 0.04 \\
Phosphate, mg/dl & $5.62 \pm 1.34$ & $3.6 \pm 0.45$ & $<0.0001$ \\
Ca $\times$ P product, $\mathrm{mg}^{2} / \mathrm{dl}^{2}$ & $48.58 \pm 12.5$ & $33.2 \pm 4.5$ & $<0.0001$ \\
ALP, IU/l & $80.5(63-110)$ & $71.5 \pm 17$ & 0.27 \\
PTH, pg/ml & $87.4(33.35-186.75)$ & - & - \\
hsCRP, mg/l & $6.75(6.4-7.17)$ & $0.36(0.1-0.56)$ & $<0.0001$ \\
$\beta_{2}-$ Microglobulin, $\mathrm{mg} / \mathrm{dl}$ & $26.07 \pm 6.39$ & $0.12 \pm 0.04$ & $<0.0001$ \\
Homocysteine, $\mathrm{mg} / \mathrm{dl}$ & $22.40 \pm 6.05$ & $5.6 \pm 1.9$ & $<0.0001$ \\
Cholesterol, $\mathrm{mg} / \mathrm{dl}$ & $151.2 \pm 40.9$ & $167.65 \pm 18.5$ & 0.09 \\
Triglycerides, $\mathrm{mg} / \mathrm{dl}$ & $136.43 \pm 79.50$ & $95.90 \pm 25.8$ & 0.02 \\
Serum iron, $\mu \mathrm{g} / \mathrm{dl}$ & $54.71 \pm 21.32$ & $93.3 \pm 13$ & $<0.0001$ \\
Transferrin, $\mathrm{mg} / \mathrm{dl}$ & $184.21 \pm 48.80$ & $254 \pm 48$ & $<0.0001$ \\
TSAT, \% & $22.76 \pm 12.92$ & $26.6 \pm 6$ & 0.21 \\
Ferritin, $\mathrm{ng} / \mathrm{ml}$ & $287(150-437)$ & $176(163-189)$ & 0.01 \\
Erythrocytes, $\mathrm{n} \times 10^{6}$ & $3.36 \pm 0.46$ & $4.75 \pm 0.26$ & $<0.0001$ \\
Hemoglobin, g/dl & $10.20 \pm 1.33$ & $13.46 \pm 0.6$ & $<0.0001$ \\
Serum creatinine, mg/dl & $7.9 \pm 1.5$ & $0.8 \pm 0.2$ & $<0.0001$ \\
Plasma obestatin pre-HD $\mathrm{ng} / \mathrm{ml}$ & $3.60(3.02-7.89)$ & $11(8.56-28.60)$ & $<0.0001$ \\
Plasma obestatin post-HD, $\mathrm{ng} / \mathrm{ml}$ & $4.32(3.19-6.2)$ & $11(8.56-28.60)$ & $<0.0001$ \\
\hline
\end{tabular}

hsCRP = High-sensitivity C-reactive protein; ALP = alkaline phosphatase; TSAT = transferrin saturation.

tory values: serum albumin level, which may represent a response to inflammation (acute-phase reaction), and serum total iron binding capacity that reflects serum transferrin concentration and correlates significantly with nutritional state in dialysis patients, although it also changes with inflammation and iron store fluctuations. Body weight assessment and anthropometric measurements were performed 5-20 min immediately after the termination of a HD treatment, and height was obtained from the patient's chart [11].

\section{Statistical Analysis}

Statistical analyses were performed with NCSS for Windows (version 4.0), the MedCalc (version 8.0) software, and the GraphPad Prism (version 5.0) package. Data were presented as mean \pm SD for normally distributed values (at Kolmogorov-Smirnov test) and median (IQ range) for non-normally distributed values. Differences between groups were established by unpaired $t$ test for normally distributed values and by Kruskal-Wallis analysis followed by Dunn's test for non-parametric values. Spearman's correlation coefficient was searched to examine the relation between variables. Before testing correlations, all non-normally distributed values were log-transformed to better approximate normal distributions. Stepwise multiple regression analyses were performed in order to assess independent relationships. All results were considered significant if $\mathrm{p}<0.05$.

\section{Results}

\section{Characteristics of HD Patients and Controls}

The main characteristics of the study cohort are summarized in table 1. The mean age of patients was $63.9 \pm$ 16 years. Inflammatory markers, such as $\beta_{2}$-microglobulin, hsCRP as well as homocysteine and serum ferritin, were higher than values in healthy controls, whereas the main hematological (erythrocytes, hemoglobin, hematocrit) and iron (serum iron and transferrin, but not transferrin saturation, TSAT), parameters were significantly lower. The calcium/phosphorus metabolism was also significantly altered in dialysis subjects compared with healthy subjects, total serum calcium levels being lower and phosphorus and the serum $\mathrm{Ca} \times \mathrm{P}$ product being higher.

Obestatin levels were significantly lower in HD patients than in healthy subjects, both in the case of pre$\mathrm{HD}$ analysis (3.24 (2.92-7.79) vs. $11(8.56-28.60) \mathrm{ng} / \mathrm{ml}$, $\mathrm{p}<0.0001)$ and in post-HD (4.13 (2.89-5.9) vs. $11(8.56-$ $28.60) \mathrm{ng} / \mathrm{ml}, \mathrm{p}<0.0001)$. Interestingly, no significant differences were found between the levels of obestatin in 


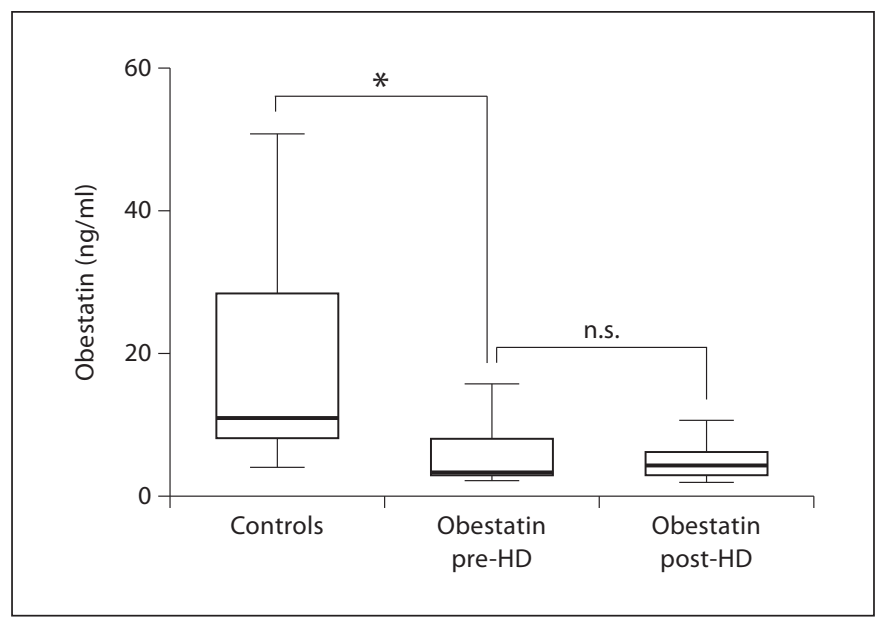

Fig. 1. Obestatin levels in HD patients were significantly lower than in healthy subjects. ${ }^{*} \mathrm{p}<0.0001$ vs. controls. No significant differences (n.s.) between the levels of obestatin in uremic patients before and after a single dialysis session $(\mathrm{p}=0.40)$.

uremic patients before and after a single dialysis session $(\mathrm{p}=0.40)$ (fig. 1).

On the basis of BMI, the patients were subdivided into two groups: those with a BMI $<23(\mathrm{n}=30)$ and those with a BMI $>23(n=20)$. In patients with a BMI $>23$, plasma obestatin values were significantly lower than those in the patients with a BMI $<23$ ( $\mathrm{p}=0.001)$ (fig. 2$)$.

\section{Univariate Correlations for Obestatin}

At univariate analysis, obestatin was found to be directly correlated with hsCRP $(\mathrm{r}=0.49, \mathrm{p}=0.0005), \beta_{2}$ microglobulin $(\mathrm{r}=0.53, \mathrm{p}=0.001)$, PTH $(\mathrm{r}=0.71, \mathrm{p}<$ $0.0001)$ and ALP $(r=0.52, p=0.0002)$, whereas significant inverse correlations were evidenced for BMI ( $\mathrm{r}=$ $-0.44, \mathrm{p}=0.002)$, serum iron $(\mathrm{r}=-0.35, \mathrm{p}=0.01)$, TSAT $(\mathrm{r}=-0.30, \mathrm{p}=0.03)$, homocysteine $(\mathrm{r}=-0.57, \mathrm{p}<0.0001)$ and the calcium-phosphate product $(\mathrm{r}=-0.48, \mathrm{p}=$ 0.0006). In contrast, no significant correlation was found for other parameters such as age, gender, MIS, cholesterol, hemoglobin, or red cells (range 0.06-0.18, p >0.06). These findings are summarized in figure 3.

\section{Multiple Regression Analysis}

All variables found to be significantly correlated with obestatin at univariate analysis were introduced in a multivariate model using obestatin as a dependent variable. After adjustment for other factors, significance was maintained for the correlation between obestatin and $\operatorname{ALP}(\beta=0.30, p=0.03)$, the calcium-phosphate product



Fig. 2. Scatterplot of obestatin values in overweight/obese HD patients (BMI $>23$ ) or normal weight/underweight subjects (BMI $<23) .{ }^{*} \mathrm{p}=0.001$.

$(\beta=-0.40, p=0.001)$, hsCRP $(\beta=0.68, p<0.0001)$ and serum iron $(\beta=-0.32, p=0.002)$. In contrast, the correlations with $\mathrm{PTH}, \beta_{2}$-microglobulin, homocysteine, TSAT and BMI, found at univariate analysis, were lost. Table 2 summarizes the data obtained.

\section{Discussion}

The findings made in the present study enable the clarification of different issues. The values for obestatin in the dialysis patients were significantly lower than those in the healthy controls. The obestatin levels were, moreover, even lower in dialysis patients with a BMI $>23$ than in those with a lower BMI. This finding could suggest that obesity and being overweight have a negative effect on obestatin production, determining a down-regulation at the gastric level as a peripheral resistance, with the consequent lack of an anorectic effect leading to weight gain. It must be said that there are no data concerning the receptor activation by obestatin in uremic patients. While the receptor through which ghrelin exerts its actions is well known, there are conflicting opinions also on the type of receptor for obestatin. Zhang et al. [12] reported that obestatin was the cognate ligand for the G-proteincoupled receptor 39 (GPR39), based on the claim of its binding to human GPR39 with high affinity and specificity. The more rapid consumption or elimination of obestatin could also be considered to explain the low lev- 


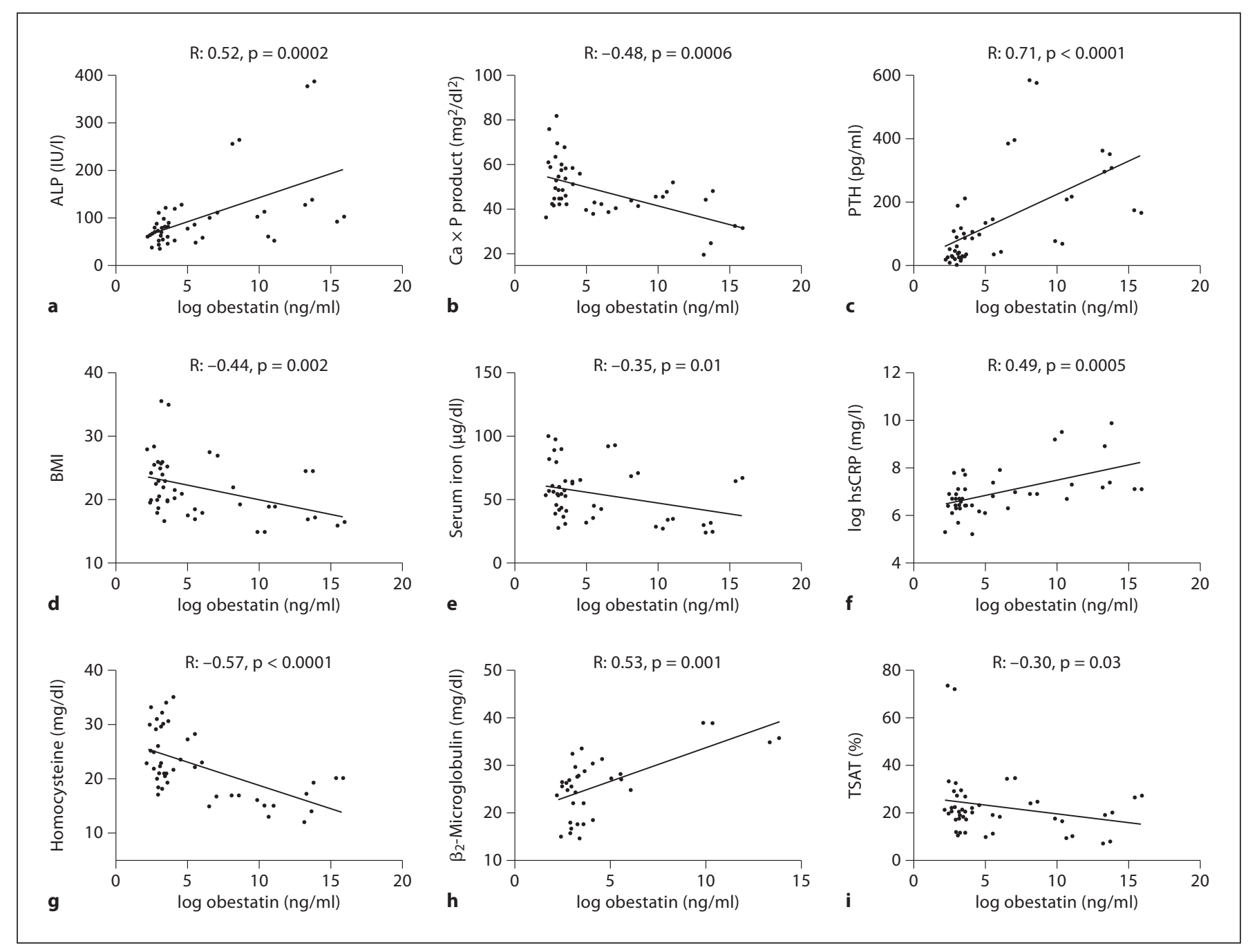

Fig. 3. Univariate relationships (Spearman's coefficient) of obestatin in HD patients. Significant correlations with $\operatorname{ALP}(\mathbf{a}), \mathrm{Ca} \times \mathrm{P}$ product (b), PTH (c), BMI (d), serum iron (e), hsCRP (f), homocysteine (g), $\beta_{2}$-microglobulin (h) and TSAT (i).

els of this hormone in uremic patients. The underlying pathomechanism remains unclear so far.

In agreement with our data, findings reported in the literature on obese nephropathic and non-nephropathic patients have demonstrated that obesity is associated with low obestatin levels [13-15], but there is also a work of Aygen et al. [16] that has instead revealed high levels of obestatin in patients undergoing dialysis compared with a control group of healthy subjects. In this work it must however be considered that there was no malnutrition in the dialysis population studied and it is interesting to note instead that there were different obestatin values between pre- and post-dialysis with a reduction after treat- ment. Moreover, in our study, no variations were found in the dialysis session, no significant change being found between the levels of obestatin before and after dialysis.

Since the correlation between obestatin and BMI disappears at multivariate analysis, BMI does not have an independent effect on obestatin - any effect probably being due to the multiple factors intervening in the network regulating the energy balance of the organism, and the balance existing between anorectic and orexigenic factors.

Our patients, analyzed from the nutritional, clinical anthropometric and laboratory standpoints, were also studied on the basis of MIS, a system that can estimate, 
Table 2. Univariate and multiple regression analysis of obestatin in HD patients

\begin{tabular}{lcccc}
\hline Variable & Partial R & p value & $\beta$ & p value \\
\hline ALPh & 0.52 & 0.0002 & 0.30 & 0.03 \\
$\begin{array}{l}\text { Calcium-phosphate } \\
\quad \text { product }\end{array}$ & -0.48 & 0.0006 & -0.40 & 0.001 \\
hsCRP & 0.49 & 0.0005 & 0.68 & $<0.0001$ \\
Serum iron & -0.35 & 0.01 & -0.32 & 0.002 \\
PTH & 0.71 & $<0.0001$ & 0.23 & 0.13 \\
$\beta_{2}$-Microglobulin & 0.53 & 0.001 & 0.22 & 0.12 \\
Homocysteine & -0.57 & $<0.0001$ & -0.70 & 0.56 \\
TSAT & -0.30 & 0.03 & -0.24 & 0.14 \\
BMI & -0.44 & 0.002 & -0.25 & 0.15 \\
\hline
\end{tabular}

Dependent variable $=$ Obestatin; $\beta=$ standardized coefficient of correlation; $\mathrm{ALPh}=$ alkaline phosphatase; hsCRP = high-sensitivity C-reactive protein; $\mathrm{PTH}$ = parathyroid hormone; TSAT = transferrin saturation; $\mathrm{BMI}=$ body mass index.

in an exhaustive and overall fashion, the presence of the complex 'malnutrition-inflammation' syndrome, and that can closely correlate with morbidity/mortality in patients who undergo HD [17].

Our data did not demonstrate a correlation between plasma obestatin levels and MIS, thus indicating that the process determining the state of inflammation and malnutrition in these patients is highly complex, being determined by various factors and not traceable to a single hormonal element, such as obestatin.

Obestatin is closely correlated with markers of inflammatory processes and, in particular, in a direct way with hsCRP and homocysteine and, inversely, with $\beta_{2}$-microglobulin. At multivariate analysis, the correlation between homocysteine and $\beta_{2}$-microglobulin is lost, while the correlation with hsCRP persists. It is known that the chronic inflammation present in uremic patients undergoing HD plays a key role, since it is a relevant factor for cardiovascular risk, and is correlated with obesity. It has been shown in various studies that obestatin plays a role in pathologic processes, without altering, at least initially, renal function in which the inflammation plays a key role from a physiopathological viewpoint, as in rheumatoid arthritis and in chronic inflammatory intestinal disease $[18,19]$. Our findings confirm this correlation, evidencing a strong and independent correlation between PCR and obestatin, thus indicating that this hormone may play a physiopathological role in the complex process of inflammation characterizing the uremic patient.
Another important inverse relation, found to be independent at multivariate analysis, emerged between serum iron and obestatin. Uremic patients are characterized by anemia, which may have a multifactorial genesis. Typically the form determined by a lack of erythropoietin, but often a concomitant iron deficit, is observed, being traceable to different factors: the reduced uptake of iron in the diet, reduced absorption, chronic gastrointestinal bleeding. It should be stressed that the gastrointestinal mucosa plays a key role in the process of iron absorption with obestatin that is precisely synthesized by the gastric mucosa. In view of the inverse levels found between serum iron and circulating obestatin, one possible explanation for this is that an up-regulation occurs in the synthesis of this hormone in response to a lack of iron. Interestingly, as demonstrated by Akarsu et al. [20], in children with iron deficiency anemia, there is a significant and positive correlation between the iron status of patients studied and the levels of the circulating obestatin antagonist, ghrelin. Furthermore, an iron deficit should, in these patients, be traceable to the chronic inflammatory process, which obestatin appears to contribute to.

Finally, obestatin was strongly correlated with some calcium-phosphorous metabolic elements. In particular, a direct correlation was found with PTH and ALP and an inverse correlation with the calcium-phosphorous product. The correlation with PTH disappeared at multivariate analysis. Typically, uremic patients have calcium and phosphorous metabolism alterations, with a picture of hypocalcemia, hyperphosphoremia, an increase in the calcium-phosphorous product and a condition of secondary hyperparathyroidism associated with parathyroid gland disease.

Vascular calcifications are, moreover, attributable to a final degenerative and passive process of atherosclerosis and chronic inflammation, characterizing the uremic patient [21]. No data are reported in the literature to confirm that obestatin plays a role in calcium-phosphorous metabolism and in the genesis and development of soft tissue calcification; its agonist, ghrelin, has, on the other hand, been the object of experimental studies, both in animals and in vitro models of vascular calcification, which demonstrate that the hormone can have a regulatory effect on the process of vascular calcification, with consequent potentially protective cardiovascular effects [22].

Calcium/phosphorous metabolism control, however, appears mediated hormonally by the parathyroid glands, through the PTH. Uremic patients have an altered para- 
thyroid function with a picture of secondary hyperparathyroidism and proliferative disease at the level of the parathyroid glands, presenting as tissue hypertrophy, and leading to adenoma/carcinoma. Volante et al. [23] demonstrated that obestatin is synthesized not only at the gastric level, but also by the endocrinal tissues, including the parathyroids.

It is reasonable to suggest that, in the uremic patient, obestatin synthesized by parathyroid cells has an autocrine-paracrine type effect, acting on the hyperplasic parathyroid tissue, through a known antiproliferative capacity, whereby it determines a protective/inhibitory effect on parathyroid disease.
In conclusion, our findings demonstrate that obestatin plays a role in different conditions that are typical of the patient with terminal renal failure, and also confirm the known involvement of this hormone on protein-energy uptake, and malnutrition; they also show how this hormone is independently correlated with markers of mineral metabolism, such as iron status and the calciumphosphorous balance, and with factors typical of the inflammatory process. Future studies are required to confirm the present data and to test the pathogenic role of obestatin in the inflammation-malnutrition complex typical of uremia in order for it to be used in the future as a possible marker in the field of nephrology, and as a consequent therapeutic target.

\section{References}

1 Zhang JV, Ren PG, Avsian-Kretchmer O, Luo CW, Rauch R, Klein C, Hsueh AJ: Obestatin, a peptide encoded by the ghrelin gene, opposes ghrelin's effects on food intake. Science 2005;310:996-999.

-2 Zhao CM, Furnes MW, Stenström B, Kulseng B, Chen D: Characterization of obestatinand ghrelin-producing cells in the gastrointestinal tract and pancreas of rats: an immunohistochemical and electron-microscopic study. Cell Tissue Res 2008;331:575-587.

-3 Ariysu H, Takaya K, Tagami T Ogawa Y, Hosoda K, Akamizu T, Suda M, Koh T, Natsui K, Toyooka S, Shirakami G, Usui T, Shimatsu A, Doi K, Hosoda H, Kojima M, Kangawa K, Nakao K: Stomach is a major source of circulating ghrelin, and feeding state determines plasma ghrelin-like immunoreactivity levels in humans. J Clin Endocrinol Metab 2001;86:4753-4758.

4 Wren AM, Small CJ, Abbott CR, Dhillo WS, Seal LJ, Cohen MA, Batterham RL, Taheri S, Stanley SA, Ghatei MA, Bloom SR: Ghrelin causes hyperphagia and obesity in rats. Diabetes 2001;50:2540-2547.

5 Kuhlmann MK, Levin NW: How common is malnutrition in ESRD? New approaches to diagnosis of malnutrition. Blood Purif 2008; 26:49-53.

6 Lacquaniti A, Bolignano D, Campo S, Perrone C, Donato V, Fazio MR, Buemi A, Sturiale A, Buemi M: Malnutrition in the elderly patient on dialysis. Ren Fail 2009;31:239245.

7 Fung F, Sherrard DJ, Gillen DL, Wong C, Kestenbaum B, Seliger S, Ball A, StehmanBreen C: Increased risk for cardiovascular mortality among malnourished end-stage renal disease patients. Am J Kidney Dis 2002; 40:307-314
>8 Qureshi AR, Alvestrand A, Divino-Filho JC, Gutierrez A, Heimbürger O, Lindholm B, Bergström J: Inflammation, malnutrition, and cardiac disease as predictors of mortality in hemodialysis patients. J Am Soc Nephrol 2002;13:28-36.

$\checkmark 9$ Kalantar-Zadeh K, Kopple JD: Relative contributions of nutrition and inflammation to clinical outcome in dialysis patients. Am J Kidney Dis 2001;38:1343-1350.

10 Kalantar-Zadeh K, Kopple JD, Block G Humphreys $\mathrm{MH}$ : A malnutrition-inflammation score is correlated with morbidity and mortality in maintenance hemodialysis patients. Am J Kidney Dis 2001;38:12511263.

$\checkmark 11$ Ho LC, Wang HH, Chiang CK, Hung KY, $\mathrm{Wu} \mathrm{KD}$ : Malnutrition-inflammation score independently determined cardiovascular and infection risk in peritoneal dialysis patients. Blood Purif 2010;29:308-316.

12 Zhang JV, Jahr H, Luo CW, Klein C, Van Kolen K, Ver Donck L, De A, Baart E, Li J, Moechars D, Hsueh AJ: Obestatin induction of early-response gene expression in gastrointestinal and adipose tissues and the mediatory role of G-protein-coupled receptor, GPR39. Mol Endocrinol 2006, 22:1464-1475.

13 Guo ZF, Zheng X, Qin YW, Hu JQ, Chen SP, Zhang Z: Circulating preprandial ghrelin to obestatin ratio is increased in human obesity. J Clin Endocrinol Metab 2007;92:18751880.

-14 Zamrazilová H, Hainer V, Sedláčková D, Papezová H, Kunesová M, Bellisle F, Hill M, Nedvídková J: Plasma obestatin levels in normal weight, obese and anorectic women. Physiol Res 2008;57:49-55.

15 Mafra D, Guebre-Egziabher F, Cleaud C, Arkouche W, Mialon A, Drai J, Fouque D: Obestatin and ghrelin interplay in hemodialysis patients. Nutrition 2010;26:1100-1144.
16 Aygen B, Dogukan A, Dursun FE, Aydin S, Kilic N, Sahpaz F, Celiker H: Ghrelin and obestatin levels in end-stage renal disease. J Int Med Res 2009;37:757-765.

17 Ho LC, Wanga HH, Pengdet YS, Chiang CK, Huang JW, Hung KY, Hu FC, Wu KD: Clinical utility of malnutrition-inflammation score in maintenance hemodialysis patients: focus on identifying the best cut-off point. Am J Nephrol 2008;28:840-846.

18 Koca SS, Ozgen M, Aydin S, Dag S, Evren B, Isik A: Ghrelin and obestatin levels in rheumatoid arthritis. Inflammation 2008;31: 329-335.

19 Alexandridis E, Zisimopoulos A, Liratzopoulos N, Katsos I, Manolas K, Kouklakis G: Obestatin/ghrelin ratio: a new activity index in inflammatory bowel diseases. Inflamm Bowel Dis 2009;15:1557-1561.

20 Akarsu S, Ustundag B, Gurgoze MK, Sen Y, Aygun AD: Plasma ghrelin levels in various stages of development of iron deficiency anemia. J Pediatr Hematol Oncol 2007;29:384387.

21 Mizobuchi M, Towler D, Slatopolsky E: Vascular calcification: the killer of patients with chronic kidney disease. J Am Soc Nephrol 2009;20:1453-1464.

22 Li GZ, Jiang W, Zhao J, Pan CS, Cao J, Tang CS, Chang L: Ghrelin blunted vascular calcification in vivo and in vitro in rats. Regul Pept 2005;129:167-176.

23 Volante M, Rosas R, Ceppi P, Rapa I, Cassoni P, Wiedenmann B, Settanni F, Granata R, Papotti M: Obestatin in human neuroendocrine tissues and tumours: expression and effect on tumour growth. J Pathol 2009;218: 458-466. 